\title{
GESTÃO POR COMPETÊNCIAS: UM ESTUDO DE CASO EM UMA INDÚSTRIA DE BEBIDAS DO BRASIL
}

\author{
CERIBELI, Harrison Bachion ${ }^{1}$ \\ TAMASHIRO, Helenita Rodrigues da Silva ${ }^{2}$ \\ BOTELHO, Amanda Almeida ${ }^{3}$ \\ REU, Jessica Souza Fernandes ${ }^{4}$
}

\begin{abstract}
RESUMO: A área de gestão de pessoas tradicional é caracterizada pela inflexibilidade e anacronismo, dificultando seu alinhamento à estratégia organizacional. Em resposta a isso, desenvolveu-se a gestão de pessoas por competências, que tem a missão de promover tal alinhamento. Este modelo gerencial, apesar de ser objeto de vários estudos e ser implantado por um número cada vez maior de organizações, ainda carece de consolidação teóricoempírica. Neste contexto, delimitou-se como objetivo desta pesquisa analisar o modelo de gestão por competências adotado por uma organização de grande porte no Brasil. O método de pesquisa utilizado foi o estudo de caso, sendo que a coleta de dados foi operacionalizada por meio da condução de duas rodadas de entrevistas direcionadas. Com base na análise dos dados, constatou-se que a coerência interna do modelo de gestão por competências implantado depende de quatro elementos principais: suporte ao desenvolvimento humano, mensuração e recompensa, recrutamento interno e carreira horizontalizada.
\end{abstract}

Palavras-chave: Competências humanas. Gestão estratégica de pessoas. Modelo de competências.

\section{COMPETENCE-BASED MANAGEMENT: A CASE STUDY IN A BEVERAGE INDUSTRY OF BRAZIL}

SUMMARY: The traditional human resources management area is characterized by inflexibility and anachronism, which hamper any attempt to align it to the organizational strategy. In response to this was developed a management model based on competences, which has the mission of promoting strategic alignment. This management model, despite being the subject of several studies and be deployed by a growing number of organizations, still lacks theoretical and empirical consolidation. In this context, the objective of this research was to analyze the competence management model adopted by a large organization in Brazil. The research method used was case study, and the data collection was operationalized by conducting two rounds of directed interviews. Based on the analysis of the collected data, it was found that the internal coherence of a competence management model depends on four main elements: support for human development, measurement and reward, internal recruitment and a structure of horizontal career.

Keywords: Human competences. Strategic human resources management. Competence model.

\section{INTRODUÇÃO}

Devido aos avanços tecnológicos contínuos e à consolidação de um sistema econômico fortemente globalizado, que culminaram em crescente competitividade e dinamismo dos mercados, tornou-se fundamental aumentar a efetividade estratégica das organizações, o que demanda total alinhamento

\footnotetext{
${ }^{1}$ Doutor em Administração pela Universidade de São Paulo (FEARP-USP) - Professor Adjunto da Universidade Federal de Ouro Preto (UFOP) - Vice-diretor do Instituto de Ciências Sociais Aplicadas (ICSA-UFOP)

${ }^{2}$ Universidade Federal de Ouro Preto - Doutora em Administração pela Universidade de São Paulo (FEA-USP)

Professora da Universidade Federal de Ouro Preto (UFOP)

${ }^{3}$ Universidade Federal de Ouro Preto - Graduanda em Administração pela Universidade Federal de Ouro Preto (UFOP)

${ }^{4}$ Graduada em Psicologia E MBA em Gestão Empresarial pela Universidade Paulista (UNIP)
} 
de todos os processos organizacionais à estratégia do negócio e, consequentemente, ruptura do tradicional anacronismo da área de gestão de pessoas (COHEN, 2015; LORZA; ORTEGA; ALVARADO, 2012).

Caso isso ocorra e a área de gestão de pessoas passe a ter orientação estratégica, as organizações tornar-se-ão capazes de desenvolverem e mobilizarem as competências dos funcionários que são mais cruciais para a estratégia do negócio, o que aumentará sua efetividade no mercado (AMORIM; SILVA, 2011).

Uma das maneiras de alinhar a gestão de pessoas à estratégia competitiva do negócio reside na adoção de um modelo de gestão por competências, que visa garantir que os conhecimentos, habilidades e atitudes dos funcionários, necessários à execução do planejamento estratégico definido, estejam disponíveis e sejam ativados em prol da organização (LORZA; ORTEGA; ALVARADO, 2012).

Gorlov, Lazareva e Fursov (2015) argumentam que, desde a década dos anos 2000, a gestão por competências tem sido amplamente estudada no meio acadêmico e implantada no meio empresarial, o que se justifica pelo fato de que o modelo de competências dá suporte à estruturação do processo de avaliação de desempenho e direciona o desenvolvimento dos funcionários, focando, em ambos os casos, em aspectos-chave para a organização.

Nesta mesma linha, Schutte, Barkhuizen e Van der Sluis (2015) tratam os modelos de gestão por competências como uma importante ferramenta de gestão de desempenho, à medida que fornecem subsídios para que os diferentes níveis de competências dos funcionários sejam mapeados e as devidas ações corretivas, tais como investimentos em programas de treinamento e desenvolvimento, sejam implantadas.

Por sua vez, Stokes e Oiry (2012) afirmam que, nas últimas décadas, as organizações dedicaram esforços para identificar, categorizar e desenvolver as competências mais relevantes de acordo com diferentes situações no ambiente empresarial, como uma forma de responder mais adequadamente à crescente demanda por qualificação profissional dos funcionários e competitividade dos negócios.

O papel central que as discussões envolvendo o tema competências adquiriram na atualidade reflete a ampliação, que tem sido observada a nível global, dos movimentos e discussões em torno dele (LIMA; ROCHA, 2012) e a busca crescente das organizações de mecanismos para medirem e desenvolverem o rol de competências de seus colaboradores (STOKES; OIRY, 2012).

Todavia, devido à elevada complexidade conceitual e prática que circundam a gestão por competências, pode-se afirmar que a mesma ainda se encontra em processo de formação teórico-empírica, apesar de haver uma tendência clara ao seu crescimento (AMORIM; SILVA, 2011), e que o movimento em torno da gestão por competências não tem sido acompanhado apropriadamente pelo desenvolvimento e consolidação de princípios e práticas que reflitam a modernidade organizacional (CASTRO; KILIMNIK; SANT'ANNA, 2008).

Mesmo em organizações que afirmam implantar a gestão por competências, ainda há predominância de práticas tradicionais e conservadoras de gestão de pessoas, tais como a remuneração funcional, ancorada exclusivamente no cargo do indivíduo, falta de critérios transparentes para promoção de funcionários, falta de alinhamento entre os programas de educação corporativa e a estratégia do negócio e entre os conteúdos dos treinamentos e as práticas correntes de trabalho, além da falta de um sistema de avaliação de desempenho formal e ancorado nas competências-chave para o negócio (CASTRO; KILIMNIK; SANT'ANNA, 2008).

Por isso, é importante dar continuidade aos estudos sobre gestão por competências, com o intuito de dar subsídios à necessária consolidação teórico-empírica do tema, justificando-se, assim, o objetivo desta pesquisa de analisar o modelo de gestão por competências adotado por uma organização de grande 
porte no Brasil.

\section{GESTÃO POR COMPETÊNCIAS}

A diversidade de abordagens e a quantidade crescente de publicações referentes à gestão por competências evidenciam sua relevância no que concerne ao desenvolvimento humano nas organizações; todavia, tanto o conceito de competência quanto sua aplicabilidade no contexto organizacional fazem parte de um arcabouço teórico-empírico ainda em fase de construção (FERRAZZA; CUNHA; PINTO, 2012), demandando análise minuciosa por parte daqueles que se propõem a estudar o tema.

$\mathrm{O}$ modelo de gestão por competências está intrinsecamente ligado à ideia de competência organizacional, que teve origem na teoria da Visão Baseada em Recursos (VBR), a qual conceitua competência organizacional como uma habilidade para fazer alguma coisa a partir dos recursos aos quais a organização tem acesso (LIMA; ROCHA, 2012). Neste novo modelo de gestão de pessoas, as competências organizacionais devem ser traduzidas em competências individuais, que deverão refletir as expectativas da organização em relação a seus funcionários (SILVA et al., 2014).

Basicamente, existem duas abordagens principais que se desenvolveram em torno do tema estudado. A abordagem norte-americana, que delimita competência como uma descrição da conduta dos funcionários que leva a elevado desempenho e das características fundamentais que levam a essa conduta, e a abordagem disseminada na Europa, que define competência como um conjunto de resultados esperados do trabalho realizado pelo funcionário (GORLOV; LAZAREVA; FURSOV, 2015).

$\mathrm{Na}$ atualidade, um dos conceitos de competência mais aceitos engloba a mobilização dos conhecimentos do indivíduo nas diferentes situações que se apresentam no trabalho, de forma que o saber (conhecimentos), o saber fazer (habilidades) e o saber agir (atitudes) estejam integrados e sejam capazes de gerar um desempenho de alto padrão (AMORIM; SILVA, 2011).

As competências possuem três características principais: estão atreladas a um contexto particular de trabalho e organizacional; associam-se a um desempenho superior; e podem ser descritas em termos de padrões comportamentais ou resultados específicos que podem ser observados no trabalho (HIRSH; STREBLER, 1994).

Na mesma linha de Hirsh e Strebler (1994), Brandão et al. (2008) argumentam que a descrição de uma competência deve representar um nível de desempenho ou padrão comportamental esperado e observável, indicando o que o profissional deve fazer. Por outro lado, Stokes e Oiry (2012) chamam a atenção para o fato de que as competências definidas não devem expressar comportamentos que podem ser replicados de forma robótica; caso contrário, o modelo de competências pode tornar-se, na prática, um manual comportamental.

Importante destacar que, no modelo de gestão por competências, a visão de que as pessoas são meros recursos a serem alocados e gerenciados é substituída pela visão de que é preciso valorizar o ser humano e compreender que suas atitudes e comportamentos são tão importantes quanto seus conhecimentos técnicos e experiências (AMORIM; SILVA, 2011).

O desenvolvimento das competências de um indivíduo pode ser avaliado a partir da ampliação de seu espaço ocupacional, pois, à medida que alguém se torna mais competente, tende a assumir atribuições mais complexas e a agregar mais valor ao negócio (LIMA; ROCHA, 2012).

De acordo com Dutra (2001), a noção de espaço ocupacional é um dos pilares da gestão por competências, além de ser uma solução às restrições organizacionais no que se refere à promoção dos funcionários, já que o indivíduo que desenvolve seu portfólio de competências, atendendo a uma demanda organizacional, pode aumentar suas atribuições e responsabilidades sem que seja necessário alterar seu 
cargo, o que não significa que sua remuneração tenha que permanecer inalterada.

Gorlov, Lazareva e Fursov (2015) e Lorza, Ortega e Alvarado (2012) defendem que a estruturação de um modelo de gestão por competências deve basear-se em uma análise preliminar da estratégia do negócio e consequente identificação das competências organizacionais críticas que se fazem necessárias para colocá-la em prática; essas, por sua vez, devem nortear a definição das competências humanas essenciais ou críticas. Tal processo de estruturação inicial faz-se importante, pois o modelo de competências definido deve garantir que os funcionários desenvolvam competências críticas, capazes de subsidiar as competências organizacionais necessárias para que a estratégia seja implantada de forma bemsucedida (AMORIM; SILVA, 2011).

Sendo assim, a implantação de um modelo de gestão por competências nas organizações deve ancorar-se no mapeamento das competências humanas essenciais e consequente formalização de uma lista de competências, que terá como papel direcionar os demais processos de gestão de pessoas (SCHUTTE; BARKHUIZEN; VAN DER SLUIS, 2015; ROSA et al., 2015).

No que se refere à lista de competências, Brandão et al. (2008) relatam a experiência bemsucedida de uma organização que trabalha com dois grupos de competências: fundamentais, que são esperadas de todos os funcionários; e específicas, que variam de acordo com a área e o cargo do profissional.

Depois de definidas as competências humanas essenciais, devem-se ajustar os processos de seleção de pessoal, desenvolvimento e avaliação de desempenho, de tal forma que estes passem a estar alinhados àquelas e, consequentemente, à estratégia organizacional (ROSA et al., 2015).

Especificamente no que se refere ao processo de seleção por competências, as entrevistas tendem a ser o método mais empregado para identificar que tipos de competências os candidatos desenvolveram ao longo de sua trajetória profissional (FERRAZZA; CUNHA; PINTO, 2012).

Em relação aos demais processos de gestão de pessoas, recomendam-se implantar (1) programas específicos de treinamento, com o intuito de desenvolver competências-chave nos funcionários, (2) um sistema de avaliação de desempenho ou certificação, que permita identificar o nível de desenvolvimento de cada competência-chave em cada funcionário, e (3) um sistema de compensação, que garanta remuneração diferenciada de acordo com o escopo de competências apresentado, individualmente, pelos funcionários (GORLOV; LAZAREVA; FURSOV, 2015).

Tais diretrizes vêm ao encontro daquelas propostas por Snitko, Gasho e Klinduhova (2015), que defendem que, para adotar um sistema de gestão pautado em competências, devem-se implantar dois programas, um para incentivar ou estimular o desenvolvimento dos funcionários, trazendo impactos para o desempenho da organização, e o outro para dar suporte a esse desenvolvimento. Em outras palavras, implantar de forma bem-sucedida um modelo de gestão por competências depende de um programa de compensação, atrelado a um programa de treinamento e desenvolvimento.

Deve-se ressaltar que os programas de treinamento e desenvolvimento ancorados nos modelos de competências devem ampliar o arcabouço sociocultural dos treinandos, garantindo que eles se tornem mais aptos a compreenderem a realidade a sua volta e ajustarem seu comportamento a diferentes situações (STOKES; OIRY, 2012).

Por sua vez, o processo de avaliação de desempenho por competências deve ser capaz de mapear o nível de desenvolvimento dos funcionários em relação a cada uma das competências definidas, possibilitando um diagnóstico preciso a respeito das lacunas existentes e da necessidade de capacitação (ROSA et al., 2015; BRANDÃO et al., 2008).

Cabe acrescentar que, no estudo conduzido por Brandão et al. (2008), é possível perceber que a avaliação de desempenho baseada em um modelo de competências mostra-se mais efetiva quando 
(1) inclui múltiplas fontes de avaliação; (2) inclui a perspectiva do avaliado, por meio da autoavaliação; e (3) os resultados obtidos são discutidos com os avaliados em reuniões de feedback.

Por isso, recomenda-se a metodologia de avaliação 360 graus, que aumenta a precisão das avaliações, à medida que o possível viés de avaliações unilaterais é minimizado, o que faz com que os próprios avaliados reconheçam que as informações obtidas no processo avaliativo são fidedignas (BRANDÃO et al., 2008).

Adicionalmente, conforme Rosa et al. (2015), é essencial que esse processo avaliativo incorpore como dimensão o desempenho histórico, considerando que o desenvolvimento das competências de cada funcionário pode ser observado de forma mais clara a partir de uma perspectiva pautada na evolução apresentada ao longo do tempo. Desta forma, ter-se-á subsídios para a condução das reuniões de feedback e orientação de carreira e para a elaboração de planos de desenvolvimento individuais.

Neste sentido, evidencia-se a relação entre a avaliação de desempenho em um sistema de gestão por competências e o foco no desenvolvimento humano, à medida que os resultados apontados no processo avaliativo permitem que cada funcionário avaliado seja localizado em uma escala gráfica que aponta seu nível de desenvolvimento atual e potencial futuro (SILVA; LUZ, 2010).

Com isso, tem-se uma visão mais clara a respeito das potencialidades dos funcionários e de suas âncoras de carreira, o que garante que os indivíduos progridam profissionalmente de maneira a alcançarem cargos alinhados a seu perfil, que pode ser mais técnico ou gerencial (SILVA; LUZ, 2010).

Em relação à remuneração atrelada ao modelo de competências, Ceribeli e Almeida (2015) e Silva e Luz (2010) destacam a importância das estruturas de carreira horizontais, com cargos apresentando gradações em termos de níveis de complexidade e exigência de entrega e níveis salariais diferenciados.

Finalizando, percebe-se que, em um modelo de gestão por competências, deve haver alinhamento entre desenvolvimento individual, remuneração e carreira, considerando que, à medida que determinado indivíduo aumenta seu escopo de competências, este se torna merecedor de maior remuneração e crescimento profissional (LIMA; ROCHA, 2012).

\section{ASPECTOS METODOLÓGICOS}

O estudo proposto neste trabalho pode ser considerado como uma pesquisa de cunho descritivo, com abordagem qualitativa. Como método de pesquisa, optou-se pela realização de um estudo de caso.

De acordo com Yin (2005), o método de estudo de caso pode ser compreendido como uma investigação empírica cujo objeto de análise é determinado fenômeno contemporâneo dentro de seu contexto real, sendo recomendado quando não é possível desvincular o fenômeno estudado e o contexto no qual ele se manifesta.

Enquanto estratégia de pesquisa, o estudo de caso abrange diferentes etapas, incluindo planejamento, coleta de dados e análise (YIN, 2005), evidenciando a necessidade de empregá-lo de forma sistemática, com o devido rigor metodológico que se faz imprescindível para que possa contribuir com a ciência.

Nesta pesquisa, realizou-se um estudo de caso descritivo, à medida que o foco da investigação foi descrever, de forma detalhada, o modelo de gestão por competências implantado na organização escolhida para fins de estudo.

A justificativa para a opção dos pesquisadores pelo estudo de caso reside no fato de que tal método permitiria aos mesmos coletar informações detalhadas a respeito de cada um dos processos de gestão de pessoas dentro de um modelo gerencial focado nas competências humanadas, identificando idiossincrasias relevantes. 
Como método de coleta de dados, utilizaram-se entrevistas direcionadas, com enfoque no modelo de gestão de pessoas por competências adotado pela empresa estudada. As entrevistas foram realizadas de forma individual com quatro analistas do departamento de Recursos Humanos. A primeira rodada de entrevistas foi realizada com base em um roteiro previamente estruturado pelos pesquisadores. Depois que os dados obtidos foram analisados, levantaram-se novos questionamentos e uma segunda rodada de entrevista foi realizada, com o intuito de elucidar pontos dúbios identificados nas entrevistas anteriores.

A empresa escolhida para realização do estudo de caso é uma indústria de bebidas de grande porte, que atua no mercado brasileiro há mais de 60 anos. Com o intuito de preservar sua identidade, essa empresa foi denominada de Gama.

Possui seis unidades localizadas na região Sudeste do Brasil, atendendo, atualmente, a mais de dois mil pontos de vendas, distribuídos em dezenas de cidades dos Estados de Minas Gerais e São Paulo, por meio de uma robusta estrutura logística.

É responsável pela geração de mais de dois mil empregos diretos, contribuindo também para as comunidades onde está instalada por meio do patrocínio a vários projetos nas áreas da educação, esporte e cultura, que beneficiam mais de seis mil pessoas. Além disso, investe em projetos de redução do uso da água e apoia cooperativas de reciclagem, evidenciando sua preocupação com a sustentabilidade.

Os princípios que norteiam a estratégia da empresa Gama incluem, dentre outros, responsabilidade (honrar os compromissos assumidos perante os stakeholders), integridade (agir de forma correta e manter a coerência entre discurso e prática), colaboração (valorizar a participação e dividir os méritos) e qualidade (buscar excelência nos produtos, pessoal e desempenho). Tais princípios são a base do modelo de competências implantado.

\section{APRESENTAÇÃO E DISCUSSÃO DOS RESULTADOS}

A partir da coleta de dados realizada na empresa Gama, verificou-se que, no processo de seleção de pessoal, são analisadas diferentes competências técnicas (que dependem das exigências de cada cargo) e comportamentais (que estão atreladas ao nível do cargo: operacional, estratégico e administrativo), todas elas definidas de forma a contribuírem com a implantação da estratégia competitiva do negócio. As competências comportamentais valorizadas para os diferentes níveis de cargos podem ser visualizadas na Figura 01.

Destaca-se que, conforme a analista de recursos humanos entrevistada, as competências comportamentais mais difíceis de serem encontradas nos candidatos são proatividade, austeridade e integridade, exigidas para todos os níveis de cargo, e orientação para resultados, demandada de profissionais no nível estratégico.

Figura 01 - Competências por nível do cargo.

(Continua)

\begin{tabular}{|c|c|}
\hline & Competências comportamentais esperadas \\
\hline & Austeridade \\
& Integridade \\
Proatividade \\
Estratégico & Trabalho em equipe \\
& Orientação para resultados \\
& Capacidade analítica \\
& Visão sistêmica \\
& Liderança \\
\hline
\end{tabular}


Figura 01 - Competências por nível do cargo.

(Conclusão)

\begin{tabular}{|c|c|}
\hline Nível do cargo & Competências comportamentais esperadas \\
\hline & Austeridade \\
& Integridade \\
Administrativo & Proatividade \\
& Comprometimento \\
& Trabalho em equipe \\
& Relacionamento interpessoal \\
& Comunicação \\
\hline & Austeridade \\
Operacional & Integridade \\
& Proatividade \\
& Comprometimento \\
\hline
\end{tabular}

Fonte: Elaboração própria, com base em informações da Empresa Gama (2016).

Ainda em relação ao processo de seleção, para mapear se os candidatos possuem ou não as competências necessárias à empresa, utilizam-se testes psicológicos e entrevistas por competências diferenciadas para cada cargo. Dependendo da complexidade do cargo, além dessas duas técnicas, são utilizados estudos de caso e rodadas de apresentações.

Entre os testes aplicados, estão a Bateria Fatorial de Personalidade (BFP), que é um instrumento construído para avaliação da personalidade a partir do modelo dos Cinco Grandes Fatores (Neuroticismo, Extroversão, Socialização, Realização e Abertura), e o DISC, que é uma metodologia que possibilita a análise comportamental das pessoas a partir de quatro fatores (Dominância, Influência, Estabilidade e Conformidade).

Como forma de valorizar o desenvolvimento humano e de motivar os funcionários a permanecerem na organização, existe uma política de priorizar o recrutamento interno. Todavia, pode-se realizar o recrutamento externo dependendo do cargo a ser preenchido (nem sempre é possível encontrar candidatos aptos internamente) e do posicionamento do gestor responsável pela solicitação de abertura do processo para preenchimento da vaga.

Para cargos mais operacionais, quando é realizado o recrutamento externo, a organização dá preferência, inicialmente, a candidatos com residência na mesma cidade daquela onde será o local de trabalho do contratado; porém, quando não é possível encontrar um profissional com as competências adequadas ao cargo e que atenda ao critério de proximidade geográfica, buscam-se candidatos aptos em outras localidades e com disponibilidade para mudança.

Para garantir que as competências técnicas e comportamentais alinhadas à estratégia do negócio sejam adequadamente desenvolvidas pelos funcionários, o departamento de gestão de pessoas trabalha com um plano anual de treinamentos, que é estruturado mediante a análise de exigências legais, dos sistemas internos de qualidade e de reuniões com os gestores, que apresentam as demandas de suas respectivas áreas. Os principais temas abordados nos treinamentos incluem: adequação às normas e procedimentos da empresa, trabalho em equipe e comunicação.

O plano anual de treinamentos utilizado pelo departamento de gestão de pessoas sofre alterações todos os anos, com o intuito de se adaptar às dinâmicas exigências do mercado, às eventuais mudanças estratégicas da organização e às lacunas de competências levantadas pelos gestores. Desta forma, os funcionários são desenvolvidos de forma continuada, adquirindo/aprimorando conhecimentos, habilidades e atitudes alinhadas às necessidades organizacionais.

Para acompanhar os resultados obtidos com os programas de treinamento e desenvolvimento 
implantados, são realizadas avaliações anuais, que visam mensurar a absorção dos conhecimentos ministrados e o aprimoramento de habilidades vinculadas ao trabalho. Também são realizados testes psicológicos para verificar mudanças no perfil comportamental dos colaboradores.

Os métodos de treinamento utilizados são normalmente presenciais e a escolha dos instrutores que irão ministrá-los depende de dois quesitos: (a) das competências técnicas e comportamentais que serão trabalhadas e de quem as possui (podem ser utilizados profissionais internos ou externos à organização); e (b) das certificações que cada colaborador possui (alguns treinamentos técnicos demandam certificações específicas dos instrutores).

Para preparar os profissionais que futuramente ocuparão cargos de gestão, a empresa estudada utiliza métodos específicos de desenvolvimento gerencial, que incluem programas de orientação de liderança e reuniões gerenciais frequentes para feedback.

A empresa estudada trabalha com o modelo de carreira em $\mathrm{Y}$, no qual o funcionário pode desenvolver sua carreira em um eixo de cargos mais técnicos ou em outro de cargos de liderança. Esse modelo de carreira é adaptado de acordo com as peculiaridades, possibilidades de crescimento e limitações de cada área.

Com a carreira em Y, é possível reter tanto os profissionais mais técnicos quanto aqueles que possuem âncora de carreira gerencial, à medida que ambos são atendidos em suas expectativas de crescimento profissional.

A estrutura de carreira na empresa também possui gradações ou níveis horizontais, sendo que cada cargo possui três níveis de desenvolvimento. Para que qualquer funcionário seja promovido para o nível imediatamente superior de sua carreira, três requisitos precisam ser atendidos: (a) deve estar exercendo a função no nível atual por, no mínimo, seis meses; (b) deve ter uma boa referência de seu gestor, que é consultado antes que a decisão acerca da possível promoção seja tomada; e (c) deve ter logrado bom desempenho na avaliação anual e nos testes comportamentais.

A avaliação de desempenho dos funcionários da empresa Gama é operacionalizada utilizando-se o método de avaliação $180^{\circ}$. Para os níveis administrativo e estratégico, o departamento de gestão de pessoas elabora os instrumentos avaliativos (questionários) de acordo com as competências críticas (técnicas e comportamentais) para o negócio e os envia para os gestores das áreas, que, por sua vez, ficam responsáveis por seu preenchimento e posterior reunião de feedback com cada um dos avaliados. Já para o nível operacional, o processo avaliativo é mais simples e reside na validação de habilidades feita pela chefia imediata.

Todos os colaboradores são avaliados, objetivando-se dar subsídios para a análise da qualidade dos programas de treinamento e desenvolvimento, assim como para as decisões relativas a promoções (verticais e horizontais) e para o Programa de Participação nos Resultados (PPR).

O PPR é um modelo de remuneração no qual os funcionários recebem um bônus anual, cujo valor depende dos resultados apresentados por eles em alguns indicadores e metas. Tanto o resultado obtido na avaliação de desempenho individual quanto o nível de alcance das metas são considerados no cálculo do bônus individual dos colaboradores no PPR.

Neste caso, percebe-se que tal programa possui características do modelo de remuneração variável (que depende do alcance de metas corporativas ou organizacionais e individuais, sendo estas últimas definidas pelos gestores de cada área) e do modelo de remuneração por competências (atrelado à contribuição que cada colaborador dá à organização, mensurada no processo de avaliação de desempenho).

Ainda no que diz respeito à remuneração, há o pagamento de um valor adicional no salário mensal dos funcionários, atrelado à assiduidade e comprometimento, para cargos operacionais. Adicionalmente, a 
empresa estudada ainda realiza campanhas pontuais com sorteios de ingressos e brindes, visando estimular a cultura entre seus colaboradores.

Os funcionários também usufruem de pacotes de benefícios ofertados pela organização, que incluem vale alimentação, restaurante na empresa, convênio médico, vale transporte e compra de produtos da empresa a preço de custo. Para aumentar a retenção dos colaboradores, a empresa Gama ainda trabalha com planos de previdência privada, possibilitando a qualquer funcionário uma remuneração adicional após a aposentadoria, complementando o benefício pago pelo Instituto Nacional de Seguro Social (INSS). Para isso, a organização estudada possui parceria com um banco privado e arca com uma parte da contribuição necessária para garantir esse benefício adicional (o funcionário também arca com uma parte da contribuição mensal que se fizer necessária).

Neste ponto da discussão, depois de apresentar os dados coletados, descrevendo o modelo de gestão por competências adotado na empresa estudada, cabe conduzir uma reflexão com base no referencial teórico construído previamente.

Primeiramente, é importante destacar que, ao contrário do que constataram Castro, Kilimnik e Sant'Anna (2008) em seu estudo de organizações que afirmaram adotar a gestão por competências, a empresa em questão abandonou determinadas práticas tradicionais e conservadoras na gestão de pessoas, esforçando-se para (a) empregar critérios claros e transparentes para promoção dos funcionários, (b) atrelar parte da remuneração dos mesmos à contribuição dada para que os objetivos organizacionais sejam alcançados, (c) alinhar os programas de treinamento e desenvolvimento à estratégia do negócio e (d) estruturar o processo de avaliação de desempenho com base nas competências-chave para a organização.

Assim como preconizam Gorlov, Lazareva e Fursov (2015), Lorza, Ortega e Alvarado (2012) e Amorim e Silva (2011), a definição das competências individuais críticas na empresa Gama está intimamente relacionada à estratégia do negócio; desta forma, o modelo de gestão pautado em competências implantado tornou-se uma ferramenta útil para alinhar objetivos individuais e organizacionais.

E, assim como defendem Schutte, Barkhuizen e Van der Sluis (2015) e Rosa et al. (2015), essas competências, depois de formalizadas, passaram a direcionar os demais processos de gestão de pessoas, tais como recrutamento e seleção, treinamento e desenvolvimento, remuneração, promoção e avaliação de desempenho.

Em relação ao processo de recrutamento na empresa Gama, cabe chamar a atenção para a política de recrutamento interno, visando aproveitar todo investimento efetuado no aprimoramento das competências dos funcionários e estimulá-los a se comprometerem com o modelo de gestão por competências implantado, que promove e valoriza o desenvolvimento humano alinhado às necessidades organizacionais (DUTRA, 2001).

De forma complementar, analisando o processo de seleção na organização estudada, destaca-se a utilização das entrevistas por competências, direcionadas de modo a mapear o nível de desenvolvimento de cada uma das competências-chave para o negócio, o que vem ao encontro das recomendações de Ferrazza, Cunha e Pinto (2012).

Já em relação ao processo de treinamento e desenvolvimento, é possível perceber que, na empresa Gama, o plano anual de treinamentos está alinhado às competências individuais críticas e, consequentemente, à sua estratégia competitiva, conforme defendem Gorlov, Lazareva e Fursov (2015) e Snitko, Gasho e Klinduhova (2015).

Além disso, ao terem foco no desenvolvimento continuado, os programas de treinamento e desenvolvimento tornam os funcionários cada vez mais aptos a interpretarem e lidarem com a realidade dinâmica na qual a organização está inserida, o que está alinhado à posição de Stokes e Oiry (2012). 
Quanto ao processo de avaliação de desempenho, evidenciam-se no caso analisado as contribuições de Rosa et al. (2015) e Brandão et al. (2008), que remetem à necessidade de alinhamento entre as competências humanas críticas e o processo avaliativo, assim como de se conduzirem reuniões de feedback, sendo ambas as providências essenciais para que seja possível identificar lacunas de desempenho e corrigi-las.

Cabe pontuar que, ao se estruturarem as reuniões de feedback com base nos resultados das avaliações de desempenho, têm-se dois benefícios imediatos: essas reuniões passam a ser direcionadas pelas lacunas de competências apresentadas pelos avaliados (ou seja, possuem direcionamento estratégico) e remetem, na prática, a orientações de carreira para os funcionários.

Ao contrário da posição de Brandão et al. (2008), que defendem que devem ser empregadas múltiplas fontes avaliativas, na empresa Gama as avaliações de desempenho são unilaterais, ou seja, apenas o superior imediato avalia cada funcionário, o que, se por um lado torna o processo mais simples e rápido, por outro, pode dar origem a distorções na avaliação, devido ao viés proveniente de se basear em uma única perspectiva a respeito do desempenho do avaliado.

Em relação à remuneração, observa-se que, na organização estudada, há duas práticas que evidenciam o esforço despendido para adequação da área de gestão de pessoas ao modelo de gestão por competências: a implantação do PPR, cujo cálculo sofre influência do desempenho obtido pelos funcionários, o qual, por sua vez, é reflexo das competências adquiridas; e a disponibilidade de programas de previdência privada, com o intuito de reter os profissionais, à medida que foram efetuados investimentos relevantes em seu desenvolvimento.

Por fim, no que se refere ao modelo de carreira na organização estudada, destaca-se a estrutura horizontalizada, apontada por Ceribeli e Almeida (2015) e Silva e Luz (2010) como elemento-chave para se alcançar coerência interna entre os processos de treinamento e desenvolvimento, avaliação de desempenho e remuneração, pois, à medida que os funcionários desenvolvem-se, logram melhores resultados nas avaliações de desempenho, passam a ter mais autonomia e a ampliar seu espaço ocupacional, e, consequentemente, almejam melhor remuneração e crescimento profissional (LIMA; ROCHA, 2012).

\section{CONSIDERAÇÕES FINAIS}

Tomando emprestado da Teoria dos Sistemas e da Abordagem Sistêmica o conceito de homeostase dinâmica, que caracteriza a busca do equilíbrio por um sistema aberto por meio de mudanças contínuas, pode-se afirmar que as organizações modernas tornaram-se muito dinâmicas, em resposta a frequentes alterações em seu ambiente competitivo, e que sua eficácia passou a depender de sua capacidade de ajustar sua estratégia e movimentos estratégicos às novas condições que lhes forem impostas.

Com isso, as diversas funções organizacionais passaram a ser pressionadas para contribuírem com a estratégia do negócio. Todavia, a área de gestão de pessoas tradicional é caracterizada pela inflexibilidade e anacronismo, os quais, por sua vez, dificultam qualquer tentativa de alinhamento à estratégia traçada pela organização. Em resposta a estas distorções, desenvolveu-se a gestão de pessoas por competências, que tem, em seus fundamentos, a missão de promover alinhamento estratégico da área.

A partir do estudo de caso realizado, pode-se perceber que a gestão por competências é implantada a partir da estratégia competitiva traçada pela organização, à medida que o primeiro passo deste processo reside na definição, com base na estratégia do negócio, de competências humanas críticas, as quais, por sua vez, irão nortear todos os processos de gestão de pessoas. É esta etapa inicial que garante o 
alinhamento estratégico da área de recursos humanos.

Também foi possível constatar que a coerência interna do modelo de gestão por competências analisado depende de quatro elementos principais: (a) suporte ao desenvolvimento humano, (b) mensuração e recompensa, (c) política de recrutamento interno e (d) carreira horizontalizada.

O suporte ao desenvolvimento humano traduz-se nos planos e programas de treinamento e desenvolvimento, que devem promover a evolução contínua dos funcionários, alicerçada sempre nas competências humanas críticas para a organização.

A mensuração diz respeito à necessidade de estruturar um sistema de avaliação de desempenho que seja capaz de mapear as lacunas, de cada funcionário, referentes às competências humanas críticas para a organização, enquanto a recompensa relaciona-se a vincular parte dos ganhos do trabalhador à contribuição real dada por ele ao negócio. Tratando esses dois elementos de forma conjunta, percebe-se que deve haver alinhamento entre o desempenho do funcionário, que reflete seu escopo de competências, e sua remuneração.

A política de recrutamento interno mostra-se essencial, pois, ao prestigiar os profissionais que já fazem parte do quadro de pessoal da organização, tende a estimular os funcionários a buscarem aprimoramento de suas competências atuais e ainda a desenvolverem outras, tornando seu escopo de competências mais completo para atender as necessidades organizacionais.

Por fim, a carreira horizontalizada, com gradações ou níveis representando diferentes graus de amplitude e complexidade da função desempenhada, garante que os funcionários sejam recompensados por aumentarem seu espaço ocupacional, sem inchar os níveis hierárquicos superiores.

Complementando o parágrafo anterior, cabe o seguinte apontamento: ao se desenvolver, o funcionário tende a aumentar o número e a complexidade das atividades que desempenha, ou seja, amplia seu espaço ocupacional (que não está necessariamente atrelado ao cargo ocupado); caso não haja uma carreira horizontal, esse indivíduo pode deixar de ser promovido, pois cada promoção implicaria, necessariamente, ascensão na hierarquia, sendo que nem sempre há espaço para isso (há limites severos para promoções verticais em qualquer organização). Neste sentido, no caso de ausência de estrutura horizontalizada, o indivíduo acaba sendo desestimulado a se desenvolver, pois o aprimoramento de suas competências (e a consequente ampliação de seu espaço ocupacional) poderia não resultar em nenhuma recompensa ou promoção.

Com os quatro elementos supracitados presentes, o modelo de gestão por competências operacionaliza-se da seguinte forma: (I) a organização estrutura um programa de treinamento e desenvolvimento robusto, capaz de aprimorar o escopo de competências dos funcionários de forma contínua e alinhada às necessidades corporativas; (II) o desempenho dos funcionários aumenta, refletindo os resultados desse programa; (III) durante o processo de avaliação de desempenho, tal evolução, em termos de desempenho, é mensurada e dá subsídios para decisões de remuneração e promoção; (IV) constatando-se que o funcionário apresentou desempenho elevado, a organização promove-o a um nível horizontalmente superior da carreira (sem implicar mudança vertical em sua posição na hierarquia); (V) após essa promoção, o indivíduo passa a ser devidamente recompensado por sua contribuição e pelo espaço ocupacional que passou a exercer como fruto de seu desenvolvimento.

Como contribuição desta pesquisa, destaca-se a identificação de elementos-chave em um modelo de gestão por competências, assim como das dinâmicas internas inerentes a ele. Para finalizar, sugere-se que estudos futuros mantenham a mesma linha de investigação aqui adotada, com o intuito de analisar outros modelos de gestão por competências e, desta forma, comparar diferentes práticas adotadas para recrutamento e seleção, treinamento e desenvolvimento, avaliação de desempenho, remuneração e promoção ancoradas nas competências humanas críticas para a organização. 


\section{REFERÊNCIAS}

AMORIM, T. N. G. F.; SILVA, L. B. Gestão por competências: nuances e peculiaridades. REUNA, v. 16, n. 1, p. 103-119, 2011.

BRANDÃO, H. P.et al. Gestão de desempenho por competências: integrando a gestão por competências, o balanced scorecard e a avaliação 360 graus. Revista de Administração Pública, v. 42, n. 5, p. 875-898, 2008.

CASTRO, J. H. M.; KILIMNIK, Z. M.; SANT'ANNA, A. S. Modernidade organizacional em gestão de pessoas como base para a incorporação de modelo de gestão por competências. RAC-Eletrônica, v. 2, n. 1, p. 105-122, 2008.

CERIBELI, H. B.; ALMEIDA, C. A. M. Gestão por competências: um estudo de caso em uma indústria no Brasil. Revista Globalización, Competitividad y Gobernabilidad, v. 9, n. 1, p. 118-130, 2015.

COHEN, D. J. HR past, present and future: a call for consistent practices and a focus on competencies. Human Resource Management Review, v. 25, n. 2, p. 205-215, 2015.

DUTRA, J. S. Gestão por competências: um modelo avançado para o gerenciamento de pessoas. São Paulo: Gente, 2001.

FERRAZZA, D. S.; CUNHA, D. L.; PINTO, M. D. Gestão por competências: a realidade vivenciada por empresas de consultoria em recursos humanos em Florianópolis/SC. Revista Pensamento

Contemporâneo em Administração, v. 6, n. 3, p. 36-52, 2012.

GORLOV, S. M.; LAZAREVA, N. V.; FURSOV, V. A. Competence-based approach to the HR management using industrial branch. Asian Social Science, v. 11, n. 7, p. 349-355, 2015.

HIRSH, W.; STREBLER, M. Defining management skills and competencies. In: MUMFORD, A. (Ed.). Handbook of Management Development, Gower: Aldershot, p. 79-97, 1994.

LIMA, M. A. M.; ROCHA, B. P. L. Avaliação de programas de gestão por competências: um estudo em organizações da Região Metropolitana de Fortaleza - CE. Organizações em Contexto, v. 8, n. 16, p. 167194, 2012.

LORZA, A. F. M.; ORTEGA, A. M. D.; ALVARADO, P. A. L. Fundamentos de un sistema de gestión humana por competencias para soportar la estrategia organizacional en una pyme del sector de la industria de las artes gráficas en Cali (Colombia). Estudios Gerenciales, v. 28, n. 122, p. 121-138, 2012.

ROSA, J. H.et al. A multi-temporal context-aware system for competence management. International Journal of Artificial Intelligence in Education, v. 25, n. 4, p. 455-492, 2015.

SCHUTTE, N.; BARKHUIZEN, N.; VAN DER SLUIS, L. The validation of a human resource management professional competence model for the South African context. Journal of Industrial Psychology, v. 41, n. 1, p. 1-9, 2015.

SILVA, L. V.; LUZ, T. R. Gestão por competências: um estudo dos impactos gerados na avaliação de desempenho e remuneração. Gestão e Sociedade, v. 4, n. 8, p. 539-561, 2010.

SILVA, A. C.et al. A gestão por competência na busca de uma organização eficaz: estudo de caso em uma universidade brasileira. Revista Globalización, Competitividad y Gobernabilidad, v. 8, n. 2, p. 102120, 2014.

SNITKO, L. T.; GASHO, I. A.; KLINDUHOVA, O. A. Competence-oriented approach to the organization's Human Resources Management in the turbulent environment. Asian Social Science, v. 11, n. 8, p. 65-71, 2015. 
STOKES, P.; OIRY, E. An evaluation of the use of competencies in human resource development - a historical and contemporary recontextualisation. Euromed Journal of Business, v. 7, n. 1, p. 4-23, 2012.

YIN, R. K. Estudo de caso: planejamento e métodos. Porto Alegre: Bookman, 2005. 